Volkers AC, Heerdink ER, van Dijk L.

Antidepressant use and off-label prescribing in children and adolescents in Dutch general practice (20012005).

Pharmacoepidemiology and Drug Safety: vol. 16, 2007, nr. 9, p. 1054-1062.

\begin{tabular}{|c|c|}
\hline Postprint Version & 1.0 \\
\hline Journal website & $\begin{array}{l}\text { http://www3.interscience.wiley.com/cgi- } \\
\text { bin/abstract/114277040/ABSTRACT?CRETRY=1\&SRETRY=0 }\end{array}$ \\
\hline Pubmed link & $\begin{array}{l}\text { http://www.ncbi.nlm.nih.gov/sites/entrez?Db=pubmed\&Cmd=ShowDetailView } \\
\text { \&TermToSearch=17551992\&ordinalpos=2\&itool=EntrezSystem2.PEntrez.Pubm } \\
\text { ed.Pubmed_ResultsPanel.Pubmed_RVDocSum }\end{array}$ \\
\hline DOI & $10.1002 / p d s .1430$ \\
\hline
\end{tabular}

\title{
Antidepressant use and off-label prescribing in children and adolescents in Dutch general practice (2001-2005)s
}

\author{
ANITA C. VOLKERS ${ }^{1 *}$, EIBERT R. HEERDINK ${ }^{2}$ AND LISET VAN DIJK ${ }^{1}$
}

\author{
${ }^{1}$ NIVEL, Utrecht, The Netherlands \\ ${ }^{2}$ Utrecht University, Department of Pharmaco-epidemiology and Pharmacotherapy, Utrecht, The \\ Netherlands \\ Correspondence to: A. C. Volkers, NIVEL P.O. Box 1568, 3500 BN Utrecht, The Netherlands. E-mail: \\ a.volkers@nivel.nl \\ ${ }^{\S}$ No conflict of interest was declared.
}

\section{SUMMARY}

Purpose To study the use of antidepressants in children and adolescents in Dutch general practice in 2001 and 2005 and to determine off-label prescribing.

Methods Data were obtained from the Netherlands Information Network of General Practice (LINH) that comprised 97 practices in 2001 and 73 practices in 2005. General practitioners (GPs) recorded prescriptions with their indication in the medical records of the patients during one calendar year. We selected boys and girls aged 0-17 years $(n=83442$ in 2001; $n=62969$ in 2005) and identified those who got prescribed antidepressants (N06A). Prevalence of use, indications and percentage of off-label prescriptions were compared between 2001 and 2005.

Results The prevalence of selective serotonin reuptake inhibitor (SSRI) use decreased from 1.2 to 1.1 per 1000 children and adolescents between 2001 and 2005. The use of tricyclic antidepressants (TCAs) and other antidepressants also decreased (0.8 to 0.7 and 0.3 to 0.2 , respectively). TCAs were often prescribed for nocturnal enuresis, but in patients aged 12-17 years hyperactivity was the leading indication in both years. GPs continued to prescribe SSRIs for depression (about half of the prescriptions) after the safety warnings, while venlafaxine prescribed for depression decreased in favour of anxiety. Off-label prescribing of SSRIs increased from $16.7 \%$ to $34.4 \%$ and that of venlafaxine from $22.2 \%$ to $58.3 \%$. All SSRI and venlafaxine prescriptions were unlicensed for age. 
Volkers AC, Heerdink ER, van Dijk L. Antidepressant use and off-label prescribing in children and adolescents in Dutch general practice (20012005).

Pharmacoepidemiology and Drug Safety: vol. 16, 2007, nr. 9, p. 1054-1062.

Conclusions The decreased use of SSRIs and venlafaxine suggests an impact of the safety warnings. A point of concern is the enlarged off-label prescribing and insight in the underlying reasons and its appropriateness is needed.

\section{INTRODUCTION}

The number of children and adolescents receiving psychotropic drugs has increased in the US and Europe during the last decade. ${ }^{1-4}$ Psychostimulants are most widely prescribed, followed by benzodiazepines and antidepressants. Most antidepressants are not licensed for the treatment of psychological problems and psychiatric disorders in patients under the age of 18 years and their efficacy and safety are under debate. ${ }^{5}$ The concern about drug safety of psychotropic drugs has grown after warnings about selective serotonin reuptake inhibitors (SSRIs) and the selective noradrenalin reuptake inhibitor (SNRI) venlafaxine. Box 1 gives an overview of (national and international) safety warnings in 2003 and 2004. ${ }^{6-11}$ Warnings of the Dutch registration authorities were also included, because we used data from Dutch general practice in our study. The safety warnings are based on a number of clinical trials that demonstrated an increased risk of adverse effects, including hostility and suicidality, in children and adolescents with major depressive disorder after the use of these newer antidepressants. Little data are available about the change in antidepressants thereafter.

Bennet et al. ${ }^{12}$ found a significant decrease in antidepressant use between 2001 and 2004 in the UK, but it was remarkable that no downward trend was observed for SSRIs. ${ }^{12}$ In contrast, Kurian et al. ${ }^{13}$ reported that there was a small decline of new users of SSRIs in 2004 as compared to 2003 in the US. $^{13}$

\section{[воX]}

The practice guidelines of the Dutch College of General Practitioners (NHG) advice GPs to refer children with depression and anxiety to childpsychiatrists and leave the diagnosing and treatment to them, but in daily practice GPs treat such cases themselves. ${ }^{14}$ In the Netherlands, only a few antidepressants are licensed to prescribe under the age of 18 years for depression and anxiety disorders. ${ }^{15}$ Furthermore, the tricyclic antidepressants (TCAs) imipramine and amitryptiline are licensed to prescribe to children for nocturnal enuresis (bed-wetting). We expected that a substantial part of the antidepressant prescriptions for children and adolescents is prescribed off-label in Dutch general practice. Off-label prescribing refers to prescribing a drug outside the terms of its marketing authorization such as prescribing for an unlicensed indication or age. An Australian study among paediatricians and child psychiatrists reported that off-label use amounted to about $40 \%$ of the physicians. ${ }^{16}$ Off-label prescribing of psychotropic drugs is also high among child psychiatrists in the Netherlands and varied from $19 \%$ for antipsychotics to $71 \%$ for antidepressants. ${ }^{17}$ Precise data about the indications for which GPs prescribe antidepressants to children and adolescents are not yet available, but children and adolescents may receive antidepressants for clinically accepted off-label indications mentioned in national guidelines. For these indications there is evidence of a good clinical trial or of efficacy, but they are not approved by the marketing authorization.

Population based studies on off-label prescribing in children and adolescents have used dispending data from pharmacists or claims data from insurance companies which do not provide the reason for prescribing.

Therefore, the focus has mainly been on off-label prescribing for age. To determine more accurately off-label prescribing for indications, information about the reason of prescribing is essential and could be obtained by physician diagnoses in the medical record of patients.

The objective of the present study was the use of antidepressants in children and adolescents and the indications for which they were prescribed in Dutch general practice. The prevalence of use was compared between 2001 and 2005. We also studied changes in physician diagnosed indications of antidepressants and determined the percentage of off-label prescriptions.

Finally, we explored the occurrence of clinically accepted off-label indications recommended in national guidelines. Data were derived from the Netherlands Information Network of General Practice 
Volkers AC, Heerdink ER, van Dijk L. Antidepressant use and off-label prescribing in children and adolescents in Dutch general practice (20012005).

Pharmacoepidemiology and Drug Safety: vol. 16, 2007, nr. 9, p. 1054-1062.

(LINH), which is a national representative database that provides medication prescriptions and the physician diagnosed indications for which drugs are prescribed. ${ }^{18,19}$

\section{METHODS}

\section{Study sample and data collection}

We used data of the LINH collected in 2001 and $2005 .{ }^{18,19}$ The LINH database holds continuous data on morbidity and prescribing about more than 350000 listed patients. Patients were comparable to the Dutch population with respect to age, gender and health insurance type. Participating GPs are spread throughout the Netherlands and representative for all Dutch GPs. In 2001, 97 general practices, enlisted 83442 children between 0 and 17 year and provided data of sufficient quality. In 2005, there were 73 participating practices with 62969 children in which 56 practices participated in both years. Prescription data were derived from the electronic medical records of the patients collected during one calendar year. Each prescription was classified according to the Anatomical Therapeutic and Chemical (ATC) Classification.

In addition, the prescription date and indication (complaint or disease) for which the drug was prescribed were recorded. Complaints and diseases were diagnosed according to the International Classification of Primary Care (ICPC). ${ }^{20}$ All children under the age of 18 years with at least one antidepressant prescription (ATC codes beginning with N06A) during the one-year registration period were identified and we selected both first prescriptions and repeats. Privacy of the participating patients was guaranteed and according to the Dutch legislation.

\section{Off-label prescribing}

To determine whether or not a prescription was off-label for indication, we consulted the medicinal products information of the Dutch registration authority. ${ }^{21}$ Information about clinically accepted offlabel indications was obtained from the Pharmaceutical Compass of the Dutch Health Care Insurance Board and the electronic prescription system of the Dutch College of General Practitioners (NHG) that is based on their national guidelines. ${ }^{22,23}$

\section{Analysis}

The prevalence of antidepressant use was calculated as the number of patients per 1000 children and adolescents with at least one antidepressant prescription in one year. To study the indications for which antidepressants were prescribed, we selected all prescriptions with a valid ICPC diagnostic code.

Subsequently, antidepressants with at least 10 ICPC coded prescriptions per year were included in the further analysis. Antidepressants that fulfilled these criteria were presented in Appendix A and Appendix B presents the ICPC codes that are linked to the indications mentioned in Appendix A. Chisquare statistics were used to study the differences in the classes of antidepressants that GPs prescribed in 2001 as compared to 2005. Logistic regression analysis was used to model the differences of off-label prescribing for indication over time controlling for differences in age and gender distribution and $p$ values less than 0.05 were considered to be significant. Analyses were performed using the statistical package SPSS (release 14.0).

\section{RESULTS}

\section{Use of antidepressants}

Table 1 presents the use of antidepressants among children and adolescents. In 2001, GPs prescribed an antidepressant 732 times to 194 patients under the age of 18 years. In 2005, we found 458 prescriptions in 124 patients. Patients who used antidepressants received on average nearly four prescriptions per year in 2001 as well as in 2005. GPs prescribed more often to girls than boys and the majority of antidepressants were prescribed to children aged 12 years and older. GPs prescribed only a 
Volkers AC, Heerdink ER, van Dijk L.

Antidepressant use and off-label prescribing in children and adolescents in Dutch general practice (20012005).

Pharmacoepidemiology and Drug Safety: vol. 16, 2007, nr. 9, p. 1054-1062.

few times for patients under the age of 6 years in both years. The [table1] overall prevalence of antidepressant use decreased from 2.3 per 1000 children and adolescents in 2001 to 2.0 per 1000 children and adolescents in 2005.

\section{[TABLE 1]}

Specifying to age group, we found a slight decrease in the prevalence in the age group 6-11 years (1.3 in 2001 vs. 1.2 in 2005). The change in prevalence in the age group 12-17 years (5.6 in 2001 vs. 4.5 in 2005) turned out to be mainly responsible for the overall decrease in prevalence.

In both years, SSRIs were the most frequently prescribed antidepressants followed by TCAs and other antidepressants (Table 2). GPs more often chose a SSRI in 2004 than in 2001: 69.9\% versus $59.8 \%$ of all prescriptions (test statistics: $\mathrm{x}^{2}=12.3, \mathrm{df}=1, \mathrm{p}<0.001$ ). The overall percentage of TCA prescriptions decreased (from $28.7 \%$ to $19.4 \%$ ), as well as that of the other antidepressant prescriptions (from $11.5 \%$ to $10.7 \%$ ). In 2001, SSRIs were mainly prescribed to the age group12-17 years (Table 2), while TCAs were merely prescribed to the age group 6-11 years. In 2005, we also found that SSRIs were mainly prescribed to the age group 12-17 years, but in the age group 6-11 years the number of SSRI and TCA prescriptions was similar. Table 2 also shows the changes in the prevalence of users of the different classes of antidepressants. TCA use decreased from 0.8 per 1000 children and adolescents to 0.7 in 2005, SSRI use decreased from 1.2 to 1.1 per 1000 children and adolescents and the use of other antidepressants decreased from 0.3 to 0.2 per 1000 children and adolescents. The largest decrease in use was found for SSRIs and TCAs in adolescents.

Imipramine was the most frequently prescribed TCA in 2001 (48.6\% of the TCA prescriptions) as well as in 2005 (56.2\% of the TCA prescriptions).

Paroxetine was the most frequently prescribed SSRI in 2001 (62.8\% of the SSRI prescriptions), while citalopram was the leading SSRI in 2005 (44.4\% of the SSRI prescriptions). Among the other antidepressants, venlafaxine was the most frequently prescribed drug in 2001 (53.6\%) as well as in 2005 (59.2\%).

\section{Indications and off-label prescribing}

There were 422 ICPC-coded prescriptions (57.7\%) in 2001 and 279 ICPC-coded prescriptions (60.9\%) in 2005. Subsequently, we selected the prescriptions for antidepressants that were prescribed at least 10 times in both years (see Appendix A for the selected antidepressants). This resulted in 354 antidepressant prescriptions in 2001 versus 255 prescriptions in 2005: 76 versus 61 TCA prescriptions, 251 versus 170 SSRI prescriptions and 27 versus 24 venlafaxine prescriptions.

\section{TCAs}

Table 3 presents the indications per type of antidepressant, by age group. Under the age of 12 years, nearly all imipramine and amitryptiline prescriptions were for nocturnal enuresis in 2001 as well as in 2005.

In the age group 12-17 years, GPs still prescribed for nocturnal enuresis, but hyperactivity as the other psychological problem (ICPC code P21) turned out to be the leading indication in both years. In 2001, tension headache (ICPC code N02) was the most frequent non-psychological indication and in 2005 this was a non-specific disease (ICPC code A99). In the total patient group, 52.6\% of the selected TCA prescriptions were off-label for indication in 2001 and this percentage decreased to $41.0 \%$ in 2005 . Under the age of 12 years the percentage off-label prescriptions was rather low: $15.6 \%$ in 2001 and $6.6 \%$ in 2004. In the highest age group the percentage of off-label prescriptions was relatively high: $79.6 \%$ in 2001 and $74.2 \%$ in 2005 . The likelihood to receive imipramine and amitryptiline for off-label indications was not significantly lower in 2005 than in 2001. GPs did not prescribe these antidepressants for the clinically accepted off-label indications neuropatic pain or tobacco abuse in 2001, but they did a few times for neuropatic pain in 2005. From the prescriptions with a licensed indication, one was prescribed off-label for age in 2001 and none in 2005. It should be mentioned that clomipramine was a frequently prescribed TCA in 2001, besides imipramine. Clomipramine was mainly prescribed for its labelled indication anxiety. However, in 2005 GPs no longer chose this antidepressant for the treatment of anxiety under 18 years. 
Volkers AC, Heerdink ER, van Dijk L. Antidepressant use and off-label prescribing in children and adolescents in Dutch general practice (20012005).

Pharmacoepidemiology and Drug Safety: vol. 16, 2007, nr. 9, p. 1054-1062.

[TABLE 2]

\section{[TABLE 3]}

\section{SSRIs}

In 2001, the majority of the selected SSRIs fluoxetine, citalopram, paroxetine, sertraline and fluvoxamine were prescribed for depression and anxiety both under and above the age of 12 years (Table 3). However, patients under the age of 12 years received SSRIs most often for anxiety, whereas patients of 12 years and older received SSRIs most often for depression. In 2005 we found another pattern. In the youngest age group, SSRIs were prescribed most often for depression, followed by other psychological problems and psychiatric disorders. The indications of other psychological problems and psychiatric disorders changed from mainly sleep disturbance (ICPC code P06) and personality disorder (ICPC code P80) in 2001 to mainly hyperactivity and other worries about the behaviour of the child (ICPC code P22) in 2005. In the older age group there was a shift between the indications depression and anxiety: GPs prescribed less often for depression and more often for anxiety in 2005 as compared to 2001. GPs also prescribed more often for other psychological problems and we observed the same change in indications for other psychological disorders as in the youngest age group.

Per year there were two SSRI prescriptions indicated for anorexia nervosa/bulimia, which is a licensed indication of fluoxetine. A minority of all SSRI prescriptions (16.7\%) was off-label for indication in 2001. The percentage of off-label prescriptions in 2005 (34.4\%) was more than two-fold in 2001, indicating that GPs were more likely to prescribe SSRIs off-label for indication than in 2001. This finding was significant (odds ratio (OR) 3.1, confidence interval (CI): 1.9-5.1, $p<0.001$ ) and independent of age and gender. Separate analyses for the age groups, provided similar patterns. The percentage off-label prescriptions between 2001 and 2005 in children aged 0-12 years increased from 28.6 to $45.5 \%$ and the percentage off-label prescriptions in adolescents aged $12-17$ from $16.0 \%$ to $32.9 \%$. SSRIs that were included in these analyses had no clinically accepted off-label indications. Because none of the selected SSRIs were registered for children or adolescents, all SSRI prescriptions were prescribed off-label for age.

\section{Venlafaxine}

Venlafaxine prescriptions had the following indications in 2001: depression (77.8\%), sleep disturbance (3.7\%) and anorexia nervosa/bulimia (18.3\%). In 2005, a different pattern was found: depression (41.7\%), anxiety (37.5\%), drug abuse (ICPC code P19) (8.3\%) and other indication (12.5\%). Venlafaxine was not prescribed to children under 12 years. In 2001, 22.2\% of the prescriptions were off-label, while in 2005 this percentage was 58.3\%. Logistic regression analysis demonstrated that GPs were indeed more likely to prescribe off-label in 2005 as compared to 2001 (OR=7.2 CI: 1.6-32.1, $p<0.01)$ while controlling for differences in age and gender distributions between the years. Anxiety is a clinically accepted off-label indication of venlafaxine. In 2001, GPs did not prescribe venlafaxine for anxiety, whereas they did more than one-third of the time in 2005. All venlafaxine prescriptions were prescribed under the licensed age of 18 years.

\section{DISCUSSION}

The findings of this study showed that the use and off-label prescribing of antidepressants in children and adolescents changed in Dutch general practice between 2001 and 2005. The prevalence of use decreased for all classes of antidepressants along the study period. The decreased SSRI and venlafaxine use observed in 2005 suggests an impact of the safety warnings in 2003 and 2004. At least this finding is in contrast to the world-wide growth of these newer antidepressants, but supports the reported decline of new users of SSRIs in 2004 in the US. ${ }^{13}$ The prevalence of antidepressant use among children and adolescents in general practice in the Netherlands is lower than that in the UK. ${ }^{12}$ Based on Dutch pharmacy dispending data including prescriptions from GPs, child-psychiatrists and adolescents-psychiatrists, ${ }^{24}$ we estimated roughly that the prevalence of antidepressant use in Dutch 
Volkers AC, Heerdink ER, van Dijk L. Antidepressant use and off-label prescribing in children and adolescents in Dutch general practice (20012005).

Pharmacoepidemiology and Drug Safety: vol. 16, 2007, nr. 9, p. 1054-1062.

general practice represents more than half of the total prevalence of antidepressant use in the Dutch population under the age of 18 years. On an average, GPs prescribed annually about four prescriptions for antidepressants per patient, indicating that they prescribed antidepressants for a prolonged period of time in accordance with the Dutch national guidelines of general practice. A recent French study reported a lower number of antidepressant prescriptions in adolescents in general practice. ${ }^{25}$ The use of antidepressants under the age of 6 years was very low in both years in the Dutch general practice. This finding is in line with the low prevalence of antidepressant use in children of age group 0-5 years in France. ${ }^{26}$ In the case of TCAs, off-label prescribing did not change over time probably because TCAs are on the market for a long time. Nocturnal enuresis was the first reason for prescribing TCAs under the age of 12 years, while hyperactivity was above the age of 12 years.

Hyperactivity in the ICPC classification is used as a diagnostic code for attention deficit hyperactivity disorder (ADHD). The NHG provides no guideline for ADHD. However, the guideline of diagnosis and treatment of ADHD of the Dutch Association of Psychiatry discusses the possible effectiveness of TCAs in children with ADHD. A remarkable finding was the change of SSRI preference from paroxetine to citalopram in children and adolescents that could also be attributed to these warnings. The first warning that was released in 2003 was against paroxetine. In the cases of SSRIs and venlafaxine, there was a remarkable increase in off-label prescribing for indication between 2001 and 2005 which is a point of concern regarding drug safety. The most frequent off-label indications of SSRIs were hyperactivity and worries about the behaviour of the child. It is unclear whether GPs also used worries about the behaviour of the child as the diagnostic code for ADHD, but this seems plausible. An additional analysis demonstrated that from the SSRIs mainly fluoxetine was prescribed for the latter diagnosis. The effectiveness of fluoxetine in patients with ADHD has been studied, but is still controversial.

The strong increase in off-label prescribing of venlafaxine could mainly be attributed to prescribing for anxiety, which is a clinically accepted off-label indication anxiety. With the exception of venlafaxine, GPs prescribed seldom for clinically accepted offlabel indications in children and adolescents, while they did so for adult patients. ${ }^{27}$ Unfortunately, our data could not be compared with the previous studies regarding off-label prescribing in general practice. Those studies included offlabel prescribing for age and dose, but not for indication due to the lack of indications. ${ }^{28-30}$ Therefore, the data of this study are unique. The prescription data that we used were completed with the reason of prescribing in contrast to dispending data of pharmacists or claims data. In our opinion, this provides a more accurate and convincing basis for conclusions about off-label prescribing.

Besides off-label prescribing, this study highlights another aspect of drug safety in children and adolescents that use antidepressants. GPs do not prescribe antidepressants on a regular base: in each practice there were on an average two children who received antidepressants per year. The question arises whether GPs have enough experience and expertise with these drugs to provide adequate care.

Cohen ${ }^{31}$ concluded recently that a SSRI prescription is still a second-line option in severe and resistant forms of youth depression and that only specialists well trained in child and adolescent psychiatry should prescribe SSRIs. ${ }^{31}$ It is unknown whether the GP was the initiator of the antidepressant treatment or whether the GP repeated antidepressants that were initiated by the specialist. Nevertheless, in both cases the GP was responsible for the treatment. A reason to prescribe could be waiting lists for mental health and the expectation of GPs that antidepressants have the same efficacy in children as in adults. It should be noted that off-label prescribing does not necessarily mean inappropriate use. If there is an urgent medical reason and parents are informed properly, GPs are allowed to prescribe off-label to children and adolescent. We recommend to collect information about the appropriate and inappropriate off-label prescribing in future studies.

\section{Potential limitations}

About $60 \%$ of the antidepressant prescriptions in our analysis had a valid ICPC diagnostic code, which could be explained by inaccuracy of GPs and technical shortcomings of the electronic prescribing systems.

We do not assume that off-label prescribing was related to the missing or invalid ICPC codes, but if this would have been the case off-label prescribing was underestimated. This study presents data that were collected in general practice and does not include children and adolescents who were treated with 
Volkers AC, Heerdink ER, van Dijk L.

Antidepressant use and off-label prescribing in children and adolescents in Dutch general practice (20012005).

Pharmacoepidemiology and Drug Safety: vol. 16, 2007, nr. 9, p. 1054-1062.

antidepressants by psychiatrists or in psychiatric wards. These patients suffer from more severe psychiatric disorder than the patients in general practice and there may be differences in the indications for which antidepressants are prescribed and the amount of off-label prescriptions. Our findings are based on first prescriptions and repeats, but we did not distinguish between drugs that were initiated by the GP or initiated by the specialist and repeated by the GP. Nevertheless, in both cases GPs are responsible for the prescribed drugs and the inherent safety risks.

\section{CONCLUSIONS}

The use of SSRIs and venlafaxine in children and adolescents decreased between 2001 and 2005 in Dutch general practice. This finding suggests that safety warnings against the use of SSRIs and venlafaxine under the age of 18 years have had an impact on their use in 2005 in Dutch general practice.

\section{[KEY POINT BOXE]}

At least the observed decrease in antidepressant use is in contrast with the world-wide growth of the use of newer antidepressants. Furthermore, the change of SSRI preference from paroxetine to citalopram in children and adolescents could also be attributed to these warnings that in the first instance were against paroxetine. To our knowledge, this is the first study to report the amount of offlabel prescribing of antidepressants in general practice based on physician- diagnosed indications. A point of concern is the growing number of off-label prescriptions of SSRIs and venlafaxine in 2004 as compared to 2001.

Furthermore, all SSRI and venlafaxine prescriptions were prescribed under the recommended age of 18 years. A promising finding was that GPs nearly never prescribed under the age of 6 years. More insight in the reasons of off-label prescribing of antidepressants is needed to determine the appropriateness and inappropriateness of off-label prescribing in general practice. GPs should at least inform the parents properly in the case of off-label prescribing.

\section{[APPENDIX A]}

\section{[APPENDIX B]}

\section{ACKNOWLEDGEMENTS}

This study was supported by an unrestricted grant from ZonMw, the Netherlands Organisation for Health Research and Development ('Patient safety’ program). 
Volkers AC, Heerdink ER, van Dijk L.

Antidepressant use and off-label prescribing in children and adolescents in Dutch general practice (2001-

2005).

Pharmacoepidemiology and Drug Safety: vol. 16, 2007, nr. 9, p. 1054-1062.

\section{BOX ES, TABLES AND APPENDIX}

Information about warnings against SSRIs and SNRIs

- June 2003: Warning from the MHRA in the UK against the use of paroxetine in children. ${ }^{6}$

- December 2003: MHRA bans all the remaining SSRIs, except fluoxetine, for use in patients under the age of 18 years. $^{7}$

- December 2003: Advice of Dutch registration authority to be careful when prescribing SSRIs in children with depression.

- End of 2003 and beginning of 2004: Drugsafety of SSRIs under 18 years was debated in the Dutch government.

- March 2004: Warning from the FDA in the US to be cautious when prescribing antidepressants (both SSRIs and SNRIs) in adults and children. ${ }^{9}$

- Beginning of 2004 to mid-2004: Dutch newspapers and actuality programs paid attention to the safety warnings of antidepressants in children and adolescents.

- December 2004: Warning from the European registration authority (EMEA) not to use SSRIs and SNRIs under the age of 18 years. ${ }^{10}$

- December 2004: The Dutch registration authority decided to change the product license of all SSRIs and SNRIs. ${ }^{11}$

Table 1. Antidepressant use among children and adolescents specified to gender and age (2001-2005)

\begin{tabular}{|c|c|c|c|c|c|c|}
\hline & \multicolumn{3}{|c|}{2001} & \multicolumn{3}{|c|}{2005} \\
\hline & $\begin{array}{c}N \text { prescriptions } \\
(\%)\end{array}$ & $\begin{array}{c}N \text { patients } \\
(\%)\end{array}$ & $\begin{array}{c}\text { Mean number } \\
\text { prescriptions (SD) }\end{array}$ & $\begin{array}{c}N \text { prescriptions } \\
(\%)\end{array}$ & $\begin{array}{c}N \text { patients } \\
(\%)\end{array}$ & $\begin{array}{l}\text { Mean number } \\
\text { prescriptions (SD) }\end{array}$ \\
\hline \multicolumn{7}{|c|}{ Antidepressants } \\
\hline Boys & $301(41.1)$ & $89(45.9)$ & $3.4(2.6)$ & $133(29.0)$ & $42(33.9)$ & $3.2(2.5)$ \\
\hline Girls & $431(58.9)$ & $105(54.1)$ & $4.1(3.5)$ & $325(71.0)$ & $82(66.1)$ & $4.0(3.5)$ \\
\hline \multicolumn{7}{|c|}{ Age group (years) } \\
\hline $0-5$ & $6(0.8)$ & $4(2.1)$ & $1.5(1.0)$ & $4(0.8)$ & $3(2.4)$ & $1.3(0.6)$ \\
\hline $6-11$ & $118(16.1)$ & $36(18.5)$ & $3.3(2.6)$ & $74(16.2)$ & $25(20.2)$ & $3.0(2.5)$ \\
\hline $12-17$ & $608(83.1)$ & $154(79.4)$ & $4.0(3.3)$ & $380(83.0)$ & $96(77.4)$ & $4.0(3.4)$ \\
\hline Total group & 732 & 194 & $3.8(3.1)$ & 458 & 124 & $3.7(3.2)$ \\
\hline
\end{tabular}


Volkers AC, Heerdink ER, van Dijk L.

Antidepressant use and off-label prescribing in children and adolescents in Dutch general practice (2001-

2005).

Pharmacoepidemiology and Drug Safety: vol. 16, 2007, nr. 9, p. 1054-1062.

nivel

Table 2. Antidepressant use among children and adolescents specified to age and class of antidepressant (2001-2005)

\begin{tabular}{|c|c|c|c|c|c|c|}
\hline & \multicolumn{3}{|c|}{2001} & \multicolumn{3}{|c|}{2005} \\
\hline & $\begin{array}{c}N \text { prescriptions } \\
(\%)\end{array}$ & $N$ patients & $\begin{array}{l}\text { Prevalence of } \\
\text { use (per 1000) }\end{array}$ & $\begin{array}{c}N \text { prescriptions } \\
(\%)\end{array}$ & $N$ patients & $\begin{array}{l}\text { Prevalence of } \\
\text { use (per 1000) }\end{array}$ \\
\hline \multicolumn{7}{|c|}{ Age group ( $0-5$ years $)$} \\
\hline TCA & $2(33.3 \%)$ & 2 & & $4(100 \%)$ & 3 & \\
\hline SSRI & $4(66.7 \%)$ & 2 & & 0 & 0 & \\
\hline Other & 0 & 0 & & 0 & 0 & \\
\hline \multicolumn{7}{|c|}{ Age groups (6-11 years) } \\
\hline TCA & $71(60.2 \%)$ & 25 & 0.9 & $36(48.6 \%)$ & 16 & 0.8 \\
\hline SSRI & $41(34.7 \%)$ & 9 & 0.3 & $37(50.0 \%)$ & 8 & 0.4 \\
\hline Other & $6(5.1 \%)$ & 2 & $<0.1$ & $1(1.4 \%)$ & 1 & $<0.1$ \\
\hline \multicolumn{7}{|c|}{ Age group (12-17 years) } \\
\hline TCA & $137(22,5 \%)$ & 41 & 1.5 & $49(12.9 \%)$ & 23 & 0.9 \\
\hline SSRI & $393(64,6 \%)$ & 93 & 3.4 & $283(74.5 \%)$ & 61 & 2.8 \\
\hline Other & $78(12.8 \%)$ & 23 & 0.8 & $48(12.6 \%)$ & 15 & 0.7 \\
\hline \multicolumn{7}{|c|}{ Total group } \\
\hline TCA & $210(28.7 \%)$ & 68 & 0.8 & $89(19.4 \%)$ & 42 & 0.7 \\
\hline SSRI & $438(59.8 \%)$ & 104 & 1.2 & $320(69.9 \%)$ & 69 & 1.1 \\
\hline Other & $84(11.5 \%)$ & 25 & 0.3 & $49(10.7 \%)$ & 16 & 0.2 \\
\hline
\end{tabular}

Table 3. Indications of TCA and SSRI prescriptions (2001-2005)

\begin{tabular}{|c|c|c|c|c|c|}
\hline & \multicolumn{2}{|c|}{ TCA prescriptions $^{\mathrm{a}}$} & & \multicolumn{2}{|c|}{ SSRI prescriptions ${ }^{\mathrm{b}}$} \\
\hline & $2001(n=32)$ & $2005(n=30)$ & & $2001(n=13)$ & $2005(n=22)$ \\
\hline \multirow{9}{*}{$\begin{array}{l}\text { Age group 0-11 years } \\
\text { Depression } \\
\text { Anxiety } \\
\text { Nocturnal enuresis } \\
\text { Other psychological problem/ } \\
\text { psychiatric disorder } \\
\text { Other indication } \\
\text { Off-label for indication }\end{array}$} & & & Age group 0-11 years & & \\
\hline & - & - & Depression & $15.4 \%$ & $54.5 \%$ \\
\hline & - & - & Anxiety & $53.8 \%$ & $4.5 \%$ \\
\hline & $84.4 \%$ & $93.4 \%$ & $\begin{array}{l}\text { Other psychological problem/ } \\
\text { psychiatric disorder }\end{array}$ & $7.7 \%$ & $27.3 \%$ \\
\hline & $3.1 \%$ & $3.3 \%$ & Anorexia/bulimia & - & - \\
\hline & $12.5 \%$ & $3.3 \%$ & Other indication & $23.1 \%$ & $13.6 \%$ \\
\hline & $15.6 \%$ & $6.6 \%$ & Off-label for indication & $30.8 \%$ & $45.5 \%$ \\
\hline & \multicolumn{2}{|c|}{ TCA prescriptions } & & \multicolumn{2}{|c|}{ SSRI prescriptions } \\
\hline & $2001(n=44)$ & $2005(n=31)$ & & $2001(n=238)$ & $2004(n=158)$ \\
\hline \multicolumn{3}{|l|}{ Age group $12-17$ years } & Age group $12-17$ years & & \\
\hline Depression & $4.5 \%$ & $3.2 \%$ & Depression & $70.6 \%$ & $53.2 \%$ \\
\hline Anxiety & - & - & Anxiety & $13.0 \%$ & $22.8 \%$ \\
\hline Nocturnal enuresis & $15.9 \%$ & $22.6 \%$ & $\begin{array}{l}\text { Other psychological problem/ } \\
\text { psychiatric disorder }\end{array}$ & $2.5 \%$ & $9.5 \%$ \\
\hline $\begin{array}{l}\text { Other psychological problem/ } \\
\text { psychiatric disorder }\end{array}$ & $27.3 \%$ & $35.5 \%$ & Anorexia/bulimia & $0.8 \%$ & $1.3 \%$ \\
\hline Other indication & $52.3 \%$ & $38.7 \%$ & Other indication & $13.0 \%$ & $13.2 \%$ \\
\hline Off-label for indication & $79.6 \%$ & $74.2 \%$ & Off-label for indication & $16.0 \%$ & $32.9 \%$ \\
\hline
\end{tabular}

${ }^{\text {a Imipramine and amitriptyline. }}$

${ }^{\mathrm{b}}$ Fluoxetine, citalopram, paroxetine and fluvoxamine. 
Volkers AC, Heerdink ER, van Dijk L.

Antidepressant use and off-label prescribing in children and adolescents in Dutch general practice (2001-

2005).

Pharmacoepidemiology and Drug Safety: vol. 16, 2007, nr. 9, p. 1054-1062.

\section{KEY POINTS}

- The LINH is a unique and representative database that provides prescriptions as well as indications for which drugs are prescribed.

- The use of SSRIs and venlafaxine among children and adolescents in Dutch general practice decreased between 2001 and 2005 and the first choice SSRI became citalopram instead of paroxetine probably due to the warnings about the increased risk of hostility and suicidality.

- A point of concern is the high percentage off-label prescribing of SSRIs and venlafaxine in 2005 as compared to 2001.

- All SSRI and venlafaxine prescriptions were prescribed under the recommended age of 18 years.

- More insight in the reasons of off-label prescribing of antidepressants is needed to determine the appropriateness and inappropriateness of off-label prescribing in general practice. GPs should at least inform the parents properly in case of off-label prescribing.

\section{APPENDIX A}

Licensed indications and ages (drug specific) of antidepressants with 10 or more prescriptions with a valid ICPC code in 2001 and 2005.

\begin{tabular}{|c|c|c|}
\hline Antidepresssants & ATC code & $\begin{array}{l}\text { Licensed indications and } \\
\text { recommended minimum } \\
\text { age per indication }\end{array}$ \\
\hline \multicolumn{3}{|l|}{ TCAs } \\
\hline Imipramine & N06AA02 & $\begin{array}{l}\text { Depression, } 12 \text { year; } \\
\text { nocturnal enuresis, } 5 \text { year }\end{array}$ \\
\hline Amitryptiline & N06AA09 & $\begin{array}{l}\text { Depression, } 12 \text { year; } \\
\text { nocturnal enuresis, } 5 \text { year }\end{array}$ \\
\hline \multicolumn{3}{|l|}{ SSRIs } \\
\hline Fluoxetine & N06AB03 & $\begin{array}{l}\text { Depression, } 18 \text { year; anxiety, } \\
18 \text { year; bulimia, } 18 \text { year }\end{array}$ \\
\hline Citalopram & N06AB04 & Depression, 18 year \\
\hline Paroxetine & N06AB05 & $\begin{array}{l}\text { Depression, } 18 \text { year; anxiety, } \\
18 \text { year }\end{array}$ \\
\hline Fluvoxamine & N06AB08 & $\begin{array}{l}\text { Depression, } 18 \text { year; anxiety, } \\
18 \text { year }\end{array}$ \\
\hline \multicolumn{3}{|l|}{ Other antidepressants } \\
\hline Venlafaxine & N06AX16 & Depression, 18 year \\
\hline
\end{tabular}


Volkers AC, Heerdink ER, van Dijk L. Antidepressant use and off-label prescribing in children and adolescents in Dutch general practice (20012005).

Pharmacoepidemiology and Drug Safety: vol. 16, 2007, nr. 9, p. 1054-1062.

APPENDIX B

ICPC codes used for the licensed off-label indications.

\begin{tabular}{ll}
\hline Indication & Coding according to the ICPC classification \\
\hline Anxiety & $\begin{array}{l}\text { P01, anxious feeling; P74 anxiety disorder; } \\
\text { P75, somatization disorder; P79, phobia/ } \\
\text { compulsive disorder }\end{array}$ \\
Depression & $\begin{array}{l}\text { P03, depressive feeling; P76 depression } \\
\text { Nocturnal enuresis }\end{array}$ \\
Neuropathic pain & $\begin{array}{l}\text { N03, pedwetting/enuresis } \\
\text { N94, peripheral neuritis; S70, herpes zoster }\end{array}$ \\
Bulimia & T06, anorexia/bulimia
\end{tabular}

\section{REFERENCES}

1. Zito JM, Safer DJ, DosReis S, et al. Psychotropic practice patterns for youth: a 10-year perspective. Arch Pediatr Adolesc Med 2003; 157(1): 17-25.

2. Delate T, Gelenberg AJ, Simmons VA, Motherhal BR. Trends in the use of antidepressants in a national sample of commercially insured pediatric patients, 1998 to 2002. Psychiatr Serv 2004; 55(4): 387-391.

3. Hugtenburg JG, Heerdink ER, Egberts AC. Increased psychotropic drug consumption by children in the Netherlands during 1995-2001is caused by increased use of methylphenidate by boys. Eur J Clin Pharmacol 2004; 60(5): 377-379. Epub 2004 May 28.

4. Wong IC, Murray ML, Cailleri-Novak D, Stephens P. Increased prescribing trends of paediatric psychotropic medications. Arch Dis Child 2004; 89(12): 1131-1132.

5. Jureidini JN, Doecke CJ, Mansfield PR, Haby MM, Menkes DB, Tonkin Al. Efficacy and safety of antidepressants for children and adolescents. Br Med J 2004; 328(7444): 879-883.

6. Medicines and Healthcare products Regulatory Agency (MHRA). Seroxat must not be used for treatment in children.

June 2003. http://www.mhra.gov.uk/home (accessed 28 March 2007).

7. Dutch Medicines Evaluation Board. Dutch Medicines Evaluation Board advices to be careful when using SSRIs in children with a depressive disorder.[in Dutch] December 2003. URL: http://www.homer.nl/cbg-meb/index.html?taal=nl (accessed 28 March 2007).

8. Medicines and Healthcare products Regulatory Agency (MHRA). Safety review of antidepressants used by children completed. URL: http://www.mhra.gov.uk/home (accessed 28 March 2007).

9. US Food and Drug Administration (FDA). Worsening depression and suicidality in patients being treated with antidepressant.

URL: http://www.fda.gov/cder/drug/antidepressants/ AntidepressanstPHA.htm (accessed 28 March 2007).

10. European Medicine agency (EMEA). CHMP meeting on Paroxetine and other SSRIs. December 2004. URL: http:// www.cbg-meb.nl/nl/docs/nieuws/pb-paroxetine.pdf (accessed 28 March 2007).

11. Dutch Medicines Evaluation Board. Antidepressants in children.[ in Dutch] December 2004. URL: http://www.cbg-meb.nl/ nl/nieuws/index.htm (accessed 28 March 2007).

12. Bennett K, Teeling M, Feely J. Overprescribing antidepressants to children: pharmacoepidemiological study in primary care.

Br Med J 2005; 331(7530): 1451-1452.

13. Kurian BT, Arbogast PG, Ray WA, Fuchs DC, Cooper WO.

Effect of government regulatory changes on SSRI prescriptions in children. Pharmacoepidemiol Drug Saf 2006; 15 (Suppl.): S33.

14. Volkers A, de Jong A, de Bakker D, van Dijk L. Effective prescribing antidepressants in general practice. (in Dutch).

NIVEL: Utrecht, the Netherlands, 2005.

15. Dutch Medicines Evaluation Board (MEB). URL: http:// www.cbg-meb.nl/ (accessed 28 March 2007).

16. Efron $D$, Hiscock $H$, Sewell JR, et al. Prescribing of psychotropic medications for children by

Australian pediatricians and child psychiatrists. Pediatrics 2003; 111(2): 372-375.

17. Hugtenburg JG, Heerdink ER, Tso YH. Psychoactive drug prescribing by Dutch child and adolescent psychiatrists. Acta Paediatr 2005; 94(10): 1484-1487. 
Volkers AC, Heerdink ER, van Dijk L.

Antidepressant use and off-label prescribing in children and adolescents in Dutch general practice (20012005).

Pharmacoepidemiology and Drug Safety: vol. 16, 2007, nr. 9, p. 1054-1062.

18. Verheij RA, te Brake $\mathrm{H}$, Abrahamse HA, Hoogen van den $\mathrm{H}$, Braspenning J, van Althuis $\mathrm{T}$. Netherlands Information Network of General Practice. Facts and figures about general practitioner care in the Netherlands. NIVEL/WOK: Utrecht/Nijmegen, the Netherlands. URL: http://www.LINH.nl (accessed 28 March 2007).

19. Verheij R, van der Zee J. Collecting information in general practice: 'just by pressing a single button'? In Morbidity, performance and quality in primary care. Dutch general practice on stage, Westert GP, Jabaaij L, Schellevis FG (eds).

Radcliffe Publishing Ltd.: Oxon, UK, 2006: 265-272.

20. WONCA Classification Committee. ICHPPC-2-Defined inclusion criteria for the use of the rubrics of the International Classification of Health Problems in Primary care. Oxford University Press: Oxford, UK, 2003.

21. Dutch Medicines Evaluation Board (MEB). http://www.

cbg-meb.nl/uk/prodinfo/index.htm (accessed 28 March).

22. Pharmaceutical Compass of the Dutch Health Care Insurance Board. www.fk.cvz.nl (assessed 28 March 2007).

23. Dutch College of general practitioners (NHG). www.

formularium.nl/nhgevs (assessed 28 March 2007).

24. Schirm E, Tobi H, Zito JM, de Jong-van den Berg LT. Psychotropic medication in children: a study from the Netherlands.

Pediatrics 2001; 108(2): E25.

25. Mancini J, Thirion X, Masut A, et al. Anxiolytics, hypnotics, and antidepressants dispensed to adolescents in a French region in 2002. Pharmacoepidemiol Drug Saf 2006; 15(7): 494-503.

26. Levy L, Martin-Guehl C, Lechevallier-Michel N, et al. Use of psychotropic drugs in 0 to 5 years old children in Aquitaine (France): prevalence and associated factors. Pharmacoepidemiol Drug Saf 2006; 15(7): 504-509.

27. Gardarsdottir H, Heerdink ER, van Dijk L, Egberts ACG.

Indications for antidepressant drug prescribing in general practice in the Netherlands. J Affect Disord 2007; 98: 109- 115.

28. Mclntyre J, Conroy S, Avery A, Corns H, Choonara I. Unlicensed and off label prescribing of drugs in general practice.

Arch Dis Child 2000; 83(6): 498-501.

29. Ekins-Daukes S, Helms PJ, Simpson CR, Taylor MW, McLay JS. Off-label prescribing to children in primary care: retrospective observational study. Eur J Clin Pharmacol 2004; 60(5): 349-353.

30. Schirm E, Tobi H, de Jong-van den Berg LT. Unlicensed and off label drug use by children in the community: cross sectional study. Br Med J 2002; 324(7349): 1312-1313.

31. Cohen D. Should the use of selective serotonin reuptake inhibitors in child and adolescent depression be banned? Psychother Psychosom 2007; 76(1): 5-14. 